\title{
Economia de comunhão e organizações de aprendizagem: compatibilidades conceituais*
}

\author{
Marcelo Alves Lopes Sampaio** \\ Sergio Proença Leitão***
}

SUMÁRIO: 1. A primeira abordagem; 2. Sobre economia de comunhão; 3. O aprender organizacional em OAs; 4. A análise estatística; 5. A análise de conteúdo; 6. Conclusão.

SUMMARY: 1 . The first approach; 2 . About communion economy; 3. Organizational learning in LOs; 4. Statistical analysis; 5 . Content analysis;

6. Conclusion.

PALAVRAS-CHAVE: aprendizagem organizacional; organizações de aprendizagem; economia de comunhão; mudança organizacional; espiritualidade da unidade.

KEY WORDS : organizational learning; learning organizations; communion economy; organizational change; the spirituality of unity.

Com base em estudo anterior que sugeriu serem as empresas do projeto de economia de comunhão orientadas para a aprendizagem, principalmente pela qualidade de seus relacionamentos interpessoais e interorganizacionais, este artigo compara a prática daquelas empresas com o conceito de organizações de aprendizagem. Foram testadas 14 características conceituais de organizações de aprendizagem junto a funcionários e gerentes de quatro empresas do projeto, concluindo-se pela existência de considerável similaridade entre as duas concepções de organização.

\footnotetext{
* Artigo recebido em nov. 2006 e aceito em mar. 2007.

** Mestre em administração de empresas pelo IAG/PUC-Rio. Endereço: Rua General Dionísio, 44, ap. 302 - Humaitá - CEP 22271-040, Rio de Janeiro, RJ, Brasil. E-mail: malsampaio@terra.com.br.

*** Professor associado do IAG/PUC-Rio. Endereço: Rua Comendador Francisco Leal, 122, casa — Itanhangá — CEP 22641-180, Rio de Janeiro, RJ, Brasil. E-mail: proenca@iag.puc-rio.
} 


\section{Communion economy and learning organizations: conceptual compatibilities}

Based on a prior study suggesting that companies of the communion economy project are learning-oriented, mainly because of the quality of their interpersonal and interorganizational relationships, this article compares the practice of those firms with the concept of learning organizations. Fourteen conceptual characteristics of learning organizations were tested on employees and managers of four firms of the project, and considerable similarities between the two organizational concepts were detected.

\section{A primeira abordagem}

O primeiro estudo brasileiro a relacionar empresas do projeto de economia de comunhão (EdC) com aprendizagem organizacional foi o de Leitão e Kurtz (2005), assumindo o pressuposto de que a qualidade dos relacionamentos interpessoais é condição comportamental necessária ao desenvolvimento e à integração de fatores que facilitam a aprendizagem organizacional. Realizado na forma de estudo de caso, pode confirmar que a aprendizagem organizacional é, em si, resultado de um contexto organizacional multirrelacional (Callahan e Schwandt, 1999), mas também onde conhecimento, aprendizagem e mudança organizacional se apresentam de forma indissociável. Inclusive porque mudança é um processo contínuo nas empresas de EdC, derivada de sua forma de conhecer a vida empresarial.

Especificamente o estudo concluiu que a qualidade dos relacionamentos, entre todos os participantes da empresa estudada, tinha influência sobre a aprendizagem das tarefas e dos comportamentos. Tal empresa, a fundição Femaq, de Piracicaba, é considerada representante avançada daquele projeto, que tem os princípios da espiritualidade cristã como motivação para suas ações operacionais e estratégicas.

A constatação dos autores foi de que o aprender ali era fruto de uma complexa rede de relações, onde a aceitação do outro como ser legítimo na convivência, fundamento ontológico de EdC e que, em seu sentido cristão, é identificado pela palavra amor, ${ }^{1}$ estava relacionada à ambiência existente na empresa. Possibilitava a motivação e a prática do aprender que, por sua vez, ajudava a explicar a mudança sofrida pela empresa em sua adesão ao projeto (Leitão e Kurtz, 2005).

\footnotetext{
${ }^{1}$ No sentido cristão, a palavra grega agape, usada por Cristo, tem o sentido de amor-comportamento, amor-ação e não amor-sentimento, o que se traduz na aceitação incondicional do próximo, goste-se ou não dele.
} 
O estudo partiu do pressuposto de que tanto a pedagogia quanto a psicologia cognitiva e a biologia do conhecimento consideravam os relacionamentos interpessoais vinculados à aprendizagem, para facilitá-la ou dificultá-la, em qualquer organização, escolar ou empresarial, pública ou privada. E também da constatação de que estudos anteriores sobre o projeto de economia de comunhão (Gonçalves e Leitão, 2001; Almeida, 2002; Mendes, 2003; Pinto, 2004; Machado, 2006) indicavam que as formas como eram conduzidos os relacionamentos interpessoais e interorganizacionais constituíam seu principal diferencial competitivo.

Em termos conceituais, embora sem diferenciar aprendizagem organizacional (AO) de organização de aprendizagem (OA), a pesquisa acabou por sugerir, considerados os limites de um estudo de caso único, a existência de possível afinidade conceitual entre EdC e organizações que aprendem. E lembrou que a maioria dos pesquisadores de AO e de OA não chegou a explicitar a qualidade dos relacionamentos como um fator inerente ao aprender organizacional, eles o deixaram freqüentemente implícito (Leitão e Kurtz, 2005).

O estudo chamou a atenção também para o fato de os diretores da empresa estudada desconhecerem aquele conceito de aprendizagem como uma estratégia empresarial, sugerindo, em decorrência, que a aprendizagem organizacional pode ocorrer de forma mais espontânea quando determinados fundamentos e práticas relacionais ocorrem.

A presente pesquisa segue a mesma linha de investigação, mas buscando confirmar a existência de afinidade conceitual entre o projeto de EdC, em sua prática empresarial, e o conceito de organizações de aprendizagem (OA), desenvolvido por Peter Senge (1990) e outros autores. Para isso utiliza outro estudo, o de Leitão e Carvalho (1999) que, a partir do exame de 23 autores, em 30 textos acadêmicos sobre organizações de aprendizagem, identificou 14 características comuns ao conceito de OA, confrontando-os com as vivências percebidas por empresários e funcionários de empresas do projeto. As empresas escolhidas são igualmente consideradas avançadas no projeto, ou seja, mais próximas do ideário lançado por sua fundadora, a italiana Chiara Lubich. São elas, a Prodiet, distribuidora farmacêutica; a KNE Rotogine, indústria de plásticos; a Editora Cidade Nova e, novamente, a Femaq, uma fundição fornecedora da indústria automobilística. Delas, só a Femaq se situa fora do pólo Spartaco, de Vargem Grande Paulista.

Em síntese, procurou-se verificar se empresas de economia de comunhão são organizações de aprendizagem, se existe afinidade entre as duas concepções de organização, que tiveram origens inteiramente distintas. As empresas de EdC surgiram de um projeto empresarial e econômico, idealizado apenas em seus princípios espirituais e filosóficos por uma mulher de visão 
mística do mundo e a maior parte de seus empresários desconhecem os conceitos de AO e de OA. A organização de aprendizagem surgiu como uma construção conceitual ainda sob verificação empírica, ou seja, carente de rigor científico e orientada para a prática. Confronta-se, então, o que emerge de uma prática empresarial, com o que emergiu com uma preocupação prática, na busca de superposições e características comuns. A prática é o ponto comum entre as duas concepções de organização.

\section{Sobre economia de comunhão}

O projeto de economia de comunhão teve origem no movimento dos focolares, movimento carismático filiado à Igreja Católica idealizado no ano de 1943, quando sua fundadora, a italiana Chiara Lubich, reunia-se com outras jovens nas ruínas de sua casa, em Trento, para organizar a ajuda às vítimas dos bombardeios aliados. Em 1991, Chiara Lubich lançou, no Brasil, o projeto de economia de comunhão, a versão empresarial-econômica daquele movimento, porque era preciso levar seus princípios à ação concreta e transformadora.

Existiam em fins de 2005, no mundo, 735 empresas filiadas ao projeto, a grande maioria com até 50 funcionários e não mais de 20 empresas com até 100 empregados. A Itália é o país com mais empresas, 230, seguida do Brasil com 121 empresas vinculadas e da Argentina, com 55, a grande maioria de pequeno porte.

O projeto tem em Vargem Grande Paulista seu escritório central no Brasil e as empresas a ele vinculadas crescem a uma taxa de $7 \%$ ao ano; no mundo, a 13\%, considerado o período 1991-2005. Segundo esse escritório, em 2005, 70\% dessas empresas registradas faturaram até US\$ 500 mil anuais. Somente quatro empresas faturaram acima de US\$ 50 milhões anuais.

O setor de serviços é o mais representado, com quase $50 \%$ dos registros, seguido da indústria com pouco mais de $25 \%$, mas as empresas do projeto estão presentes em todos os setores da atividade econômica.

No esforço de síntese de Bruni (2005:25) a economia de comunhão busca uma nova relação entre mercado e sociedade ao desafiar as ideologias dominantes na era da globalização. São empresas privadas inseridas no mercado, que salvaguardam a propriedade particular dos bens, mas colocam o lucro em comunhão. Tais empresas constituiriam uma prática de humanismo no mundo dos negócios.

Há certa superposição entre essa concepção de organização e a de Gustavsson (2002), de que o entendimento das organizações deve se basear na consciência transcendente do homem, como numa epistemologia transcen- 
dente das organizações, pois toda organização tem origem na consciência humana. Não são entidades externas a nós, humanos, mas uma decorrência natural da consciência humana, pois ser humano significa ser social, ser grupal, requerendo formas organizadas de existência. No ideário de EdC, isso se realiza através do princípio da espiritualidade da unidade, que tem a ver com o nível mais profundo de nossa consciência e com o conhecimento como experiência transcendente no dizer de Gustavsson (2002). Existe aí uma curiosa coincidência na forma de ver as organizações produtivas. E esse vínculo com o transcendente, parece ser a origem da impressão positiva que os pesquisadores que convivem com os empresários e funcionários dessas empresas trazem delas, incluindo aí a nossa própria observação pessoal. Esses pesquisadores as consideram empresas diferentes se comparadas às organizações de orientação instrumentalista, de viés tecnicista e economicista no trato com as pessoas. $\mathrm{O}$ diferente está na forma como as pessoas se tratam umas às outras, incluindo clientes, fornecedores e outros stakeholders (Pinto e Leitão, 2006) e as implicações que isso tem em suas decisões estratégicas.

Existe nessas empresas maior espaço para a palavra, para a convivência entre o objetivo e o subjetivo e menor repressão à interioridade dos indivíduos. Tal comportamento observável nos reporta a pesquisadores que atuam nas áreas da psicanálise e da psicopatologia do trabalho como Laurent Lapierre, Christophe Dejours, Alain Chanlat ou Rennée Bedard, que trouxeram para os estudos organizacionais a questão da interioridade e do sofrimento no trabalho, ou ainda a da liberdade de expressão. Foram os humanistas que enfatizaram a importância de uma gestão fundada na aceitação do outro, na compreensão e na empatia (Lapierre, 1994:253).

Os princípios filosóficos-espirituais pelos quais se procura operar essas empresas foram fixados por Chiara Lubich, líder do movimento e do projeto, em diversos textos (Lubich, 2002, 2004) e discutidos e aprofundados por diversos autores, principalmente por economistas italianos. Mas é também interessante vê-los na perspectiva mais operacional de alguns de seus empresários e funcionários.

Henrique Leibholz, da Femaq, diz que a EdC traz algo a mais para a empresa, pois as pessoas trabalham mais satisfeitas, uma vez que percebem que não se trata apenas de uma questão de custo-benefício. Sobre a diferença de EdC, diz ele:

são os princípios éticos, de relacionamento, de desenvolvimento de produtos evoluídos tecnicamente. O produto tem limitações, mas a qualidade é maximizada pois desenvolvemos produtos juntos. É uma postura. Esta postura acaba atraindo clientes, pois nós estamos sempre correndo atrás de 
melhorias. Uma empresa de EdC não fica no mínimo necessário. Temos de otimizar, dentro das restrições de mercado.

Pinto (2004:176)

Seu irmão Rodolfo Leibholz, acrescenta:

Nós não temos regras, temos princípios; o principal deles é o bem comum. Outro é o amor recíproco, fazer as coisas em unidade. Nosso tipo de administração é uma coisa viva (...) Se você pegar algo que não tenha a ver com o princípio da vida, ele vai ser expulso (...) É nisso que acreditamos.

Pinto (2004:177)

A Femaq mantém altos índices de produtividade (Gonçalves e Leitão, 2001) e é conhecida também por sua preocupação ambiental, além da social (Pinto e Leitão, 2001:74), pois como diz o mesmo Rodolfo "nós não interagimos com o ambiente (...) nós somos o ambiente", mostrando claro conhecimento da visão trazido pelo movimento da ecologia profunda (Capra, 1997:23).

O estudo de Gonçalves e Leitão (2001) nessa empresa obteve algumas opiniões de funcionários e operários sobre ela, das quais se podem extrair: uma empresa totalmente diferente na forma de administrar; um lugar onde o contato entre funcionários, gerentes e diretores é sempre próximo; uma empresa que investe nas pessoas e onde se sabe o que está acontecendo; uma organização que não visa só o lucro; uma empresa formada por gente simples, que se preocupa com o bem-estar dos funcionários e que tem uma filosofia de gestão que estimula os funcionários a pensarem mais no próximo.

Para Armando Tortelli, da Prodiet, "a EdC tem como objetivo, em primeiro lugar, a partilha. Isso é fácil de fazer, ainda que exija alguns cuidados. Agora o importante é o funcionário saber onde vai o dinheiro da empresa, que há um capital social que está sendo dividido" (Pinto, 2004:197). Sobre o compromisso da empresa com o emprego, a possível substituição de funcionários por salários menores ou a demissão por idade, ele afirma “(...) mas se a empresa não tiver um objetivo social, o ganhar dinheiro pelo dinheiro não me realiza" (Gonçalves, 2005:163).

A baixa coerção e a qualidade dos relacionamentos no ambiente de trabalho da Prodiet também são lembradas por Tortelli, quando diz que

o que importa é tirar das pessoas o que elas têm de bom, potencializar o aspecto positivo, fazer com que elas se sintam felizes com seu trabalho, sendo naturalmente tratadas como profissionais, elogiadas, cobradas e tudo mais (...) O que não condiz com o modo da gente agir, com o nosso proce- 
der, aos poucos eles vão percebendo, se não vierem a perceber é saber conviver com um pensamento diferente do nosso.

Gonçalves (2005:150)

Na Prodiet, como em outras empresas do projeto "o objetivo é passar os valores intrínsecos para as pessoas, mais do que falar da EdC" (Pinto e Leitão, 2006:83). Diz Armando Tortelli:

após esses 10 anos podemos assegurar que a EdC pode, sim, dar vantagens competitivas. Isso não é possível de ser copiado. Não é possível instrumentalizar o conceito. A EdC exige que os proprietários (empresários) tenham esses valores dentro de si (...) As pessoas se motivam porque acreditam nessa causa.

Pinto (2004:197)

Em síntese, “a EdC coloca o homem no centro de nossas atividades. A motivação normalmente é vista como um meio para a empresa atingir seus objetivos. Aqui isso é um fim" (Pinto, 2004:199).

Sobre a empresa, diz um de seus funcionários,

justamente porque tenho consciência dos objetivos da empresa, eu me sinto responsável, não apenas para com o proprietário-gerente, ou com os colegas de trabalho, mas para com todas as pessoas que são beneficiadas com o trabalho da Prodiet...

Gonçalves (2005:168)

Ainda sobre a motivação do trabalhador e os relacionamentos, diz outro: "uma das coisas que me motiva trabalhar aqui é ver que essa empresa está para atender, ela está em prol da dignidade, ela está para ajudar o ser humano a viver melhor..." (Gonçalves, 2005:168). E outro funcionário acrescenta:

Isso é um diferencial, a empresa é ética. Ética nos relacionamentos com os clientes, com os funcionários. A Prodiet não reduz custos cortando pessoal, ela busca alternativas. Isso dá certa segurança aos funcionários. Mas o Armando (diretor) não é paternal, pelo contrário, ele se faz respeitar. As pessoas não estão aqui porque ele é bonzinho.

Pinto (2004:202)

Esses depoimentos, extraídos de teses de doutorado, permitem ver as ambiências de trabalho e os tipos de relacionamentos interpessoais ali desenvolvidos, pois é na gestão de pessoas que está o maior diferencial dessas em- 
presas. O que os pesquisadores que estudaram EdC percebem, é que problemas existem, sobretudo entre os funcionários e gerentes mais novos, ainda não absorvidos pela chamada "cultura da partilha" ou "cultura do dar", que caracteriza as empresas mais avançadas no ideário de Chiara Lubich, e é preocupação central de seus dirigentes. Entre esses ainda existe alguma desconfiança, mas o senso comum é de que os níveis de conflitos interpessoal e interorganizacional, incluindo empresas e sindicatos, ficam bem abaixo das empresas de culturas que estimulam a competitividade interpessoal. A percepção que se tem no exame dos estudos produzidos sobre essas e outras empresas do projeto, além do estudo específico de Leitão e Kurtz (2005), é de que são culturas favoráveis à aprendizagem.

Os depoimentos dos funcionários naqueles, como neste estudo, nos reportam a Hardy e Clegg (2001:305) quando se referem a pesquisas que sugerem ser a habilidade diferenciadora das pequenas organizações a habilidade para aprender; ou quando se reportam a Bennis e a Wesley (p. 306), ao tratar da liderança, e se referem a um gerenciamento mais afinado com a atividade de ouvir, aprender e provocar conversações, em vez de comandar e controlar. Há evidências nessas empresas de EdC de que o sujeito está sendo ressuscitado, com o ser humano deixando de ser mercadoria e o mercado empurrado para seu devido lugar, que é o das trocas de bens e serviços, sem penetrar todas as dimensões da vida associada. E este parece ser o grande potencial transformador embutido nesse projeto.

Por outro lado, aprendizagem não se dissocia de mudança e são as empresas de pequeno porte as consideradas mais capacitadas para a implementação de mudanças transformadoras. Land e Jarman (1997:225), em seu modelo de transformação de três fases, constataram que as empresas com maior capacidade para alcançar o mais alto nível de transformação são as de pequeno porte e periféricas, ou então divisões de grandes corporações. As empresas de EdC são majoritariamente de pequeno porte e estão mostrando proatividade nesse tipo de mudança, com um conhecimento orientado por uma visão espiritual do mundo de negócios, o que, por si só, já é uma transformação. O que se conclui dos estudos sobre EdC acima citados é que esse projeto empresarial e econômico tem como objetivo colocar o ser humano e o bem comum como o centro de todo o processo de produção e distribuição da riqueza. Todo o seu aprendizado é voltado para esse objetivo maior. E também que para entendê-la e teorizar sobre ela é preciso apreender o significado da espiritualidade da unidade, princípio da doutrina cristã e do movimento dos focolares incorporado pelas lideranças da vanguarda do projeto (Machado, 2006). 


\section{O aprender organizacional em OAs}

O conceito de organização de aprendizagem (OA) é, em certa medida, uma decorrência da preocupação com a aprendizagem nas organizações (AO), que emerge nos anos 1970, com raízes, na corrente do desenvolvimento organizacional (DO), onde despontavam Paul Lawrence, Jay Lorsch, Warren Bennis. Além de Chris Argyris e Donald Schon, estes os principais expoentes da transição para $\mathrm{AO}$.

E viria a se tornar presença constante na literatura organizacional dos anos 1990, constituindo a AO a principal corrente sobre o tema aprendizagem. Cohen e Sproul (1991) afirmariam, então, que as teorias sobre aprendizagem ofereciam uma alternativa positiva aos pressupostos da escolha racional, pois poderiam explicar como os pressupostos organizacionais, as estruturas cognitivas e as ações afetam e são afetadas por processos institucionais menos racionais, embora igualmente importantes.

Como é comum nos estudos organizacionais, a literatura sobre aprendizagem surge de forma fragmentada sem uma visão integrativa e claramente direcionada, além de ser pouco rica no exame da ontologia do fenômeno no âmbito das empresas de finalidade econômica. Já em 1978, Argyris e Schon alertavam para a necessidade de uma visão sintética da aprendizagem que permitisse sua integração à teoria organizacional.

Foi no desenvolvimento dessas visões fragmentadas, embora unificadas em sua perspectiva epistêmica, porque foram dominadas por uma orientação positivista e estrutural-funcionalista, que surgiu a proposta de Peter Senge, em 1990, quando introduziu a idéia de que a aprendizagem organizacional deveria ocorrer nas organizações de aprendizagem (OA). Elas seriam um lugar onde as pessoas continuamente expandem sua capacidade de criar resultados que verdadeiramente desejam, onde padrões de pensamento ampliado são nutridos, onde a aspiração coletiva é libertada e onde as pessoas estão continuamente aprendendo a aprender. Para caracterizá-la desenvolveu suas conhecidas cinco disciplinas: domínio pessoal, modelos mentais, objetivo comum, aprendizado em grupo e raciocínio sistêmico, a quinta disciplina que integraria as demais (Senge, 1990:14).

Com sua proposta, Senge modifica o conceito vigente de aprendizagem organizacional, deslocando-o para o contexto de uma organização e, com isso, lhe dá novo significado. O novo conceito gerou mais de duas dezenas de adeptos, entre eles, Ray Stata, George Huber, Bárbara Levitt, James March, Ikujiro Nonaka, George Romme, John Dillen, David Garvin e Peter Hawkins. Mas Senge ficaria conhecido como o principal idealizador do conceito de OA, depois testado por ele e sua equipe do Massachusetts Institute of Technology (MIT) em 
Boston, teste que foi precedido pela publicação de seu caderno de campo (Senge et al., 1999).

Para se tornar um conceito efetivo, capaz de propiciar mudanças transformadoras, ele teria de deslocar os modelos mentais vigentes, com seus valores pessoais, cultura, sistema de poder e a ideologia autoritária, da forma de organização capitalista dominante, para o paradigma humanista (Villardi e Leitão, 2000). Kofman e Senge (1993) dizem que, entre os alicerces que suportam uma organização de aprendizagem, está uma cultura baseada em valores humanos transcendentes de amor, surpresa, humildade e compaixão; e também um conjunto de práticas que possibilitem conversação generativa e ação coordenada.

Tais alicerces têm pontos em comum com os princípios propagados pelo projeto de economia de comunhão. Além do que, tanto o conceito de OA, de Senge, quanto os princípios e as práticas de EdC, trazem a idéia de transformação da ordem estabelecida, do jogo bruto dos mercados e da busca por uma empresa e um sistema produtivo mais humanizado. No caso de Senge, a origem de sua inspiração substantiva parece estar na filosofia zen-budista que ele pratica.

A ética de Senge volta-se para a confraternização universal de todos os sistemas, unidos apenas da aparente diversidade, na medida em que todo ser humano é um ser social e conseqüentemente tem natureza sistêmica. Ele acredita numa unidade possível, transcendendo as diferenças (Villardi e Leitão, 2000), o que para o projeto de economia de comunhão corresponderia ao princípio fundamental da espiritualidade da unidade como uma nova proposta para o agir econômico (Lubich, 2004:29). E nada disso tem a ver com objetivos manipulativos da alta gerência no fixar objetivos comuns a toda a organização. Tem a ver com uma visão filosófica otimista do ser humano, que encontra respaldo na visão biológica da teoria dos sistemas vivos quanto à natureza humana. Ou seja, tem a ver também com a organização de nosso sistema nervoso e nossa condição de ser social, que requer a aceitação do outro como ser legítimo no conviver e também altruísmo, pois precisamos ceder espaços nesse convívio (Maturana e Varela, 1995; Maturana e Bunnell, 1998; Maturana, 2001).

O conceito desenvolvido por Peter Senge contém uma proposta de transição do ver funcionalista para o ver humanista, de natureza emancipadora, apoiada no pensamento sistêmico de forma a permitir uma autocrítica constante, com mudança no nível de consciência e constante construção e reconstrução da realidade organizacional e social. Nas idéias norteadoras de sua arquitetura organizacional para a aprendizagem existem muitos termos afins com os de EdC, entre eles: irmandade, vida comunitária, compaixão, unidade, 
tradições espirituais, ou ainda, prática da verdade. Como também no vocabulário de Hawkins (1991), onde há referências ao emocional e ao espiritual no nível substantivo de aprendizagem ali sugerido (aprendizado de nível III), que transcende o mundo do ego para se definir o indivíduo e as dimensões da vida.

Em suma, há pontos conceituais comuns entre OA e EdC, embora, no ideário de EdC, a aprendizagem apareça implicitamente no que denominam "formação de um homem novo" que significa para Chiara Lubich (2002:54) "pessoas que tenham o carisma da unidade na própria alma e que possam dálo a mancheias, de modo a transformar o mundo, a nossa sociedade". O aprender está presente nas práticas das empresas do projeto, mesmo que não se perceba a presença de aprendizagem como um elemento estratégico explícito de suas gestões.

\section{A análise estatística}

Este estudo seguiu o mesmo método utilizado por Leitão e Kurtz (2005), com uma abordagem quantitativa (estatística descritiva) e qualitativa no uso da análise de conteúdo. No primeiro momento da pesquisa foram aplicados questionários junto a diretores, supervisores e gerentes das quatro empresas estudadas com 14 perguntas referentes às 14 características extraídas do estudo de Leitão e Carvalho (1999). E também um questionário de seis perguntas para funcionários administrativos e operários com os temas mais ajustados ao seu nível de percepção da empresa entre as 14 características citadas. Este objetivava também fazer comparações com as respostas dos representantes da gerência dessas empresas.

Ambos os questionários utilizaram a escala Likert de cinco níveis, tendo sido aplicados, ao todo, 57 questionários, sendo 13 para o nível hierárquico mais alto e 44 para o mais baixo, distribuídos entre as quatro empresas, representando $63 \%$ dos seus funcionários. Os entrevistados justificaram suas respostas nos dois casos.

As 14 características extraídas do estudo já citado foram apresentadas aos entrevistados da seguinte forma, fazendo-se esclarecimentos quando necessário.

Geração de conhecimento: a busca da produção e aprimoramento de técnicas e procedimentos, tanto no nível do fazer (objetivo) quanto no nível das idéias (subjetivo).

Transferência de conhecimento: capacidade para idealizar o que foi criado na empresa com as conseqüências diretas e indiretas para a tarefa e para o setor de atividade e a capacidade de adaptar as novas idéias à realidade de cada um. 
Transformação do conhecimento: se a empresa tem capacidade de transformar o conhecimento gerado em resultados práticos que proporcionem ações coerentes e com maior probabilidade de sucesso.

Comprometimento das lideranças: se as lideranças falam a mesma língua quanto às operações da empresa e se comprometem e se empenham para o desenvolvimento e implantação de uma consciência de aprendizado.

Objetivos coletivos: quando a missão da empresa, as metas estratégicas e os objetivos dos diferentes setores são sempre assumidos como coletivos; e se existe abertura para a discussão sobre as opiniões e os desejos dos empregados.

Solidariedade, abertura ao conhecimento e sinceridade: a existência de um compromisso ininterrupto com a transferência das ações, bem como uma busca contínua de melhoria dos processos entre todos os envolvidos, inclusive quanto ao comprometimento das pessoas de alguma forma ligadas à empresa.

Posicionamento positivo quanto aos erros: se a empresa se posiciona positivamente ante a fracassos e erros e se existe uma postura de plena disposição para tirar proveito deles.

Coexistência harmoniosa e produtiva de opiniões diferentes: se as diferentes opiniões coexistem sem conflitos e se há um clima de apoio à introdução de novas idéias em todos os níveis da empresa.

Clima de abertura e valorização da verdade: quando as comunicações são abertas e a verdade é perseguida como premissa básica em todos os debates e decisões.

Padronização e homogeneização dos meios de comunicação: se os meios de comunicação são padronizados e homogêneos para o entendimento coletivo, se existe uniformização das expressões utilizadas e técnicas de diálogo que facilitem a comunicação interna.

Consistência objetiva e conteúdo técnico das observações: se as decisões são baseadas em fatos concretos que sejam aceitos pelos debatedores.

Autocrítica e humildade: existência de autocrítica, humildade e aceitação por parte de diretores e gerentes na eterna condição de aprendizagem; se ao encontrar dificuldades para realizar uma tarefa, procura-se ajuda; se ante uma situação complexa, procura-se o diálogo com os colegas para sua solução.

Busca de visões alternativas: se a empresa foge do condicionamento para respostas óbvias e procura mais enriquecimento do processo decisório.

Aprendizado em grupo: o desenvolvimento do diálogo e de um pensamento coletivo para o grupo conseguir realizações maiores do que teriam seus 
membros isoladamente; se uma pessoa sente que produz mais quando trabalha em equipe do que individualmente.

\begin{tabular}{|lccc|}
\hline \multicolumn{4}{c}{ Tabela 1} \\
\multicolumn{4}{|c|}{ Percepção de todos os } \\
& entrevistados \\
\hline Características de organização de aprendizagem & Média & Mediana & Desvio-padrão \\
\hline Aprendizado em grupo & 4,9231 & 5 & 0,2774 \\
Clima de abertura e verdade & 4,8462 & 5 & 0,3755 \\
Geração de conhecimento & 4,7692 & 5 & 0,4385 \\
Solidariedade, abertura, sinceridade & 4,7692 & 5 & 0,4385 \\
Coexistência harmoniosa de opiniões diferentes & 4,7692 & 5 & 0,4385 \\
Consistência objetiva e conteúdo técnico das observações & 4,7692 & 5 & 0,4385 \\
Existência de objetivos coletivos & 4,6923 & 5 & 0,4804 \\
Busca de visões alternativas & 4,6923 & 5 & 0,4804 \\
Comprometimento das lideranças & 4,6154 & 5 & 0,5064 \\
Posicionamento positivo diante dos erros & 4,6154 & 5 & 0,5064 \\
Autocrítica e humildade & 4,5385 & 5 & 0,5189 \\
Transformação do conhecimento & 4,4615 & 4 & 0,5189 \\
Transferência de conhecimento & 4,3846 & 4 & 0,5064 \\
Padronização e homogeneização dos meios de comunicação & 4,3077 & 4 & 0,6304 \\
\hline
\end{tabular}

Tabela 2

\section{Percepção dos funcionários e operários para seis características}

\begin{tabular}{llcc}
\hline Características de organização de aprendizagem & Média & Mediana & Desvio-padrão \\
\hline Aprendizado em grupo & 4,6047 & 5 & 0,6226 \\
Clima de abertura e verdade & 4,2558 & 4 & 0,7896 \\
Comprometimento das lideranças & 4,2093 & 4 & 0,6384 \\
Coexistência harmoniosa de opiniões diferentes & 4,186 & 4 & 0,6639 \\
Existência de objetivos coletivos & 4,186 & 4 & 0,7639 \\
Transferência de conhecimento & 3,6512 & 4 & 0,9483 \\
\hline
\end{tabular}

O resultado da percepção dos funcionários, diretores e gerentes, quanto ao que ocorre nas quatro empresas da amostra, no que se refere às 14 características, está na tabela 1. E o resultado para as seis características selecionadas apenas para funcionários e operários, está na tabela 2 .

Apesar dos indícios anteriores do estudo de Leitão e Kurtz (2005) os resultados não deixaram de surpreender os pesquisadores. Nos dois casos, as médias foram altas, muito concentradas nas opções "concordo" e "concordo 
totalmente". As respostas dos funcionários e operários ratificaram as dos diretores e gerentes. Há pouca dispersão nas respostas a cada característica e as médias máximas e mínimas não estão muito distantes entre si nas 14 características, com a única exceção da característica "transferência de conhecimento" nas respostas dos funcionários (tabela 2). Esse foi o item crítico da pesquisa, apresentando algumas dúvidas e ressalvas nos dois grupos examinados. Sobre isso, vejamos dois exemplos extraídos das justificativas apresentadas na marcação da escala Likert pelos entrevistados: "Leva-se algum tempo para (as idéias) serem totalmente compreendidas e incorporadas" (supervisor); "Nem todas as ações são entendidas no seu contexto integral por todos" (auxiliar administrativo).

Mas há evidências também de que estão buscando superar tais limitações, pois essas empresas, apesar de serem consideradas das mais avançadas no ideário do projeto ainda estão em um processo de aprendizado na maneira EdC de ser, que é, para todas, um aprendizado.

As tabelas também mostram que nas características de uma organização de aprendizagem "aprendizado em grupo" e "clima de abertura e verdade", nos dois grupos, ocorre o contrário: não há nenhuma discrepância quanto a suas presenças nas quatro empresas. Todavia, em uma perspectiva mais crítica, pode-se verificar que ocorreram algumas justificativas onde não fica claro se foi feito referência a uma prática, ou a um objetivo a alcançar. Exemplo para o caso de "clima de abertura e valorização da verdade": "O principal objetivo da empresa é a formação e divulgação dos princípios do carisma da unidade, isto é, que todos sejam um" (gerente contábil).

Mas as justificativas de significado claro foram bem mais presentes do que as sujeitas a uma interpretação ambígua. A existência de confiabilidade nas justificativas dadas é a posição a que se chega, principalmente após a análise da segunda fase da pesquisa, que utilizou a análise de conteúdo categorial, critério semântico (Bardin, 1977), em abordagem qualitativa. Sobre a confiabilidade pode-se também agregar o conhecimento de estudos anteriores sobre a ambiência existente nessas empresas e, provavelmente, o fato de que três das empresas estudadas estão em um mesmo pólo. Embora não tenham sido notadas diferenças entre elas e a Femaq, situada em Piracicaba. A hipótese aqui levantada é de que essa proximidade física tenha, além das implicações conhecidas quanto às facilidades de infra-estrutura e prática de ajuda mútua, uma possível influência sobre a motivação de suas gerências. Tal proximidade, sugerida por Chiara Lubich, reforçaria o sentido de união.

Nessa segunda fase foram feitas 13 entrevistas em profundidade, abrangendo $15 \%$ do universo de operários, funcionários e gerentes das quatro em- 
presas. A análise do conteúdo dos depoimentos trouxe reforço aos resultados do estudo estatístico e as justificativas ali apresentadas, desestimulando uma volta ao campo para novas entrevistas.

\section{A análise de conteúdo}

A análise subjetiva, com a técnica categorial, levou à definição de 12 categorias, extraídas dos depoimentos, respeitando-se as regras de exclusão mútua, homogeneidade, pertinência, objetividade, fidelidade e produtividade (Bardin, 1977:120). Sua pertinência em relação ao material de análise reflete a intenção da investigação, ou seja, a busca da identificação das características das organizações de aprendizagem nas empresas do projeto de EdC. A seguir, as categorias emergentes da análise das entrevistas, seus significados e relações percebidas com outras categorias.

Ambiente: trata das citações sobre o clima organizacional no momento da pesquisa, refletindo um ambiente de trabalho produtivo e harmonioso; o comprometimento das lideranças com esse clima, onde gerentes e funcionários sentem-se confortáveis para se expressar e agir, sem medo de julgamentos. São feitas comparações com experiências em outras empresas fora do projeto.

Autocrítica: é a necessária manutenção do processo de aprendizagem e do desenvolvimento pessoal, implicando uma postura crítica ante a complexidade dos problemas cotidianos com a necessária humildade. Foi relacionada, nos depoimentos, com as categorias "diálogo" e "valores".

Coletividade: mentalidade de que todos são responsáveis pela ação e resultados da empresa, que o atinjimento de uma meta comum envolve dependência e interconectividade entre departamentos. Envolve um sentimento de unidade e se relaciona com todas as outras categorias.

Compartilhamento: identifica um senso de comunidade, participação, comprometimento e interação das pessoas. Tem implicações para a multiplicidade de idéias e se inter-relaciona com as categorias "liberdade" e "abertura".

Comunicação: a forma como a organização comunica seus procedimentos e decisões; se há padronização e homogeneização dos meios de comunicação. Tem implicações para o entendimento coletivo, transparência e sentido de comunidade. Relaciona-se com a categoria "compartilhamento".

Crescimento: é o desenvolvimento total do indivíduo, indo além das formas de treinamento que objetivam a eficácia organizacional. O comprometimento das lideranças é necessário a esse processo de crescimento individual.

Diálogo: refere-se à busca de visões alternativas, à existência de opiniões distintas, solução de conflito, coleguismo e se relaciona com as categorias 
"abertura" e "relacionamento". Houve menções também ao comprometimento das lideranças.

Discussão: trata da consistência objetiva das decisões. Na categoria anterior, há a busca por uma nova visão, nesta o objetivo é a possibilidade de defesa de uma visão capaz de sustentar uma decisão.

Liberdade: é o indivíduo enquanto ser dotado de vontade própria, motivado a questionar e impelido a criar. Esta categoria atrai a responsabilidade, na medida em que maior liberdade envolve maior responsabilidade pelos resultados. Foi relacionada a "ambiente" nos depoimentos.

Posicionamento diante do erro: como as chefias entendem e se posicionam ou ainda tiram proveito dos erros dos funcionários. Atrai questões como punição, aprendizagem, experiência profissional e foi relacionada às categorias "valores" e "crescimento" em alguns depoimentos.

Relacionamento: são os relacionamentos interpessoais em todos os níveis e envolve questões como respeito e diversidade, sendo apontadas conexões com as categorias "diálogo" "discussão" e "posicionamento diante do erro".

Valores: diz respeito ao que influencia diretamente o pensar e o agir nas empresas. Essa categoria está implícita na visão de mundo das pessoas e nas suas ações. Houve várias vinculações ao movimento das focolares, como origem dos valores das empresas estudadas.

Seguindo a técnica categorial (Bardin, 1977), a segunda etapa da análise de conteúdo foi o agrupamento dessas categorias em famílias, conforme o gênero de temas, o que permitiu formar cinco famílias. Como diz Bardin (p. 37) o momento da escolha dos critérios de classificação depende daquilo que se procura, ou se espera encontrar, não tendo sido por acaso que as 12 categorias puderam ser classificadas em cinco famílias correspondentes às cinco disciplinas de Peter Senge (1990). Sem a perda de contato com as 14 características testadas na análise estatística, pois as 12 categorias emergiram do teste das 14 características (entrevistas).

As cinco famílias e as categorias que as compõem são: modelos mentais (valores); domínio pessoal (ambiente, autocrítica, crescimento e liberdade); visão compartilhada (compartilhamento e comunicação); aprendizagem em grupo (diálogo, discussão, posicionamento diante do erro e relacionamento); pensamento sistêmico (coletividade).

Os depoimentos que se seguem, de forma muito sintética, são representativos para cada uma dessas famílias.

Modelos mentais: o valor mais evidente nos depoimentos é o da unidade que possibilita um clima de abertura, coexistência de opiniões diferentes e solidariedade. A atitude amorosa para com o outro também é percebida, da mesma forma que se nota a influência do movimento dos focolares dentro das 
empresas com os gerentes e funcionários que dele participam, mostrando sua influência na formação de uma nova mentalidade nessas empresas.

Eu sinto que há um comprometimento dos sócios da empresa com o projeto pelo comportamento deles. Eu sinto a diferença de postura em relação a outros chefes que eu já tive (em outras empresas). E, sem saber, parece que as pessoas assimilam a postura que a gerência tem diante da empresa por causa do projeto de economia de comunhão.

(Auxiliar administrativo)

O depoimento de uma funcionária sugere que o desenvolvimento de habilidades interpessoais de aprendizagem, citado por Senge (1990:213) como fator crítico para trabalhar com modelos mentais se origina no movimento, fora da empresa. Diz ela, em certo momento:

Eu era muito isolada e não conseguia mudar minha cabeça. Mas a partir do momento em que eu comecei a participar do movimento, eu passei a discutir, debater e ouvir mais. E acabo chegando à conclusão que a idéia de outra pessoa pode ser melhor mesmo.

(Recepcionista)

Domínio pessoal: não surpreende a identificação das categorias agregadas a esta família na medida em que Senge (1990:41) afirma estar a raiz desta "disciplina" nas tradições espirituais. A preocupação com a construção de algo maior é comum nos depoimentos de gerentes e funcionários, sendo isto parte relevante do aprender: "Eu entrei (na empresa) por ser uma empresa de economia de comunhão. Eu já conhecia o projeto e veio ao encontro de um desejo meu, um sonho meu da construção de uma sociedade melhor" (gerente administrativo); "Isso (aprimoramento de todos) não acontece com todo mundo junto porque o faturamento não permite, mas junto a gente vai mostrando as prioridades" (secretária).

Os depoimentos mostram que: valoriza-se a geração de novas técnicas; existe investimento em desenvolvimento de pessoal; a decisão em quem investir é tomada em grupo; existe a percepção de que investir em uma área significa investir indiretamente em outras; existe o interesse e a procura individual para o desenvolvimento próprio e existe liberdade para o esclarecimento de dúvidas ou para críticas. E novamente a disponibilidade amorosa para o crescimento do outro, porque isso é considerado bom para todos: "Quando o funcionário se sente amado e valorizado no seu potencial, naquilo que ele pode dar, ele dá o retorno" (gerente comercial). 
A palavra amor esteve presente em vários depoimentos. Surgiu no contexto das falas sem que o interlocutor pudesse detectar a intenção de causar impressão. O tema é parte central dos fundamentos do movimento focolarino e do projeto de EdC, mas se torna aceitável porque é usado no sentido de "amor-comportamento", desapegando-o do sentido de amor-sentimento que poderia soar piegas ou apelativo na ambiência empresarial, onde tal termo é efetivamente raro. Aceitar o outro como ser legítimo na convivência do trabalho, naquele sentido, soa mais factível do que ter de gostar do outro como algo necessário à convivência. Tal postura básica na convivência é que favorece a solidariedade, a cooperação, o altruísmo, a empatia e outras formas integrativas da vida associada, caracterizadoras da "cultura da partilha" buscada por essas empresas.

Visão compartilhada: os depoimentos mostram que a visão compartilhada muda o relacionamento das pessoas com a empresa e que é necessária para eliminar desconfianças mútuas e para o trabalho em conjunto.

Eu atribuo tudo isso (senso de unidade) à nossa prática de querer deixar
tudo muito claro, transparente, bem aberto. As meninas (recepcionistas e
auxiliares administrativas) sabem dos problemas que nós temos e acabam
nos ajudando. É uma questão de partilha. Quando se chama um funcionário
para a participação desse tipo (reuniões regulares), depois fica mais auto-
mática a participação dele.

(Gerente administrativo)

Outro gerente observou, por outro lado, que reuniões impostas pouco funcionam, primeiro é necessário criar maior relacionamento, mais comunhão entre os funcionários, ou não se consegue chegar a "esse novo estilo de administração" (EdC). Segundo ele, é o espaço de comunhão que permite as trocas técnicas, reduzindo significativamente a prática de guardar conhecimento para si nas reuniões, como nos congressos e palestras.

Mas, como mostrou a média mais baixa da característica "transferência de conhecimento" no estudo estatístico, ainda existem dificuldades, percebidas em alguns depoimentos, para se chegar a essa comunhão. A força de um individualismo culturalmente desenvolvido, trazido de outras empresas, ainda se faz presente no projeto de EdC. O esforço para superá-lo, todavia, persiste. Disse uma secretária que uma vez por ano, em sua empresa, ocorre uma reunião com todos os funcionários, para cada departamento escolher três metas profissionais e três metas pessoais, para conferir o resultado no final do ano. Conclui ela "(...) às vezes a gente sai do trilho mesmo e é preciso rever o foco". 
Aprendizagem em equipe: em depoimentos em congressos de economia de comunhão ou em estudos empíricos (Leitão e Kurtz, 2005; Pinto e Leitão, 2006; Machado, 2006) o diálogo vem sendo apresentado como um elemento importante na "cultura da partilha" que essas empresas estão implantando. Os depoimentos confirmaram isso: a existência de certa facilidade para o coleguismo e amizade nas equipes de trabalho.

Existem aí pontos de contato com o que Senge (1990:264) definiu como "confiança operacional", onde membros de uma equipe permanecem conscientes de outros membros e agem de forma complementar.

Aqui é uma empresa, tem horário de trabalho, tem chefe, tem hierarquia, mas acima de tudo o relacionamento é pautado na fraternidade. Essa é que é a grande diferença. Meu maior objetivo aqui é manter e desenvolver esses relacionamentos de fraternidade.

(Gerente comercial)

Não existem diferenças das pessoas que trabalham na área administrativa, das pessoas que trabalham na área de produção. Existe uma conversa, um diálogo entre todos os funcionários.

(Auxiliar administrativo)

Isso não exclui o fato da gente não se pegar (discussão). Mas é uma coisa de se pegar para esgotar uma idéia.

(Gerente financeiro)

Por outro lado, todos os depoimentos acerca do lidar com o erro indicaram uma postura positiva tanto nos gerentes quanto nos funcionários. Os gerentes apontam a concorrência e a importância do lucro para a sobrevivência, mas a atenção no ser humano está sempre presente em suas falas.

Admitir o erro significa dar espaço para o funcionário crescer, afirmou um gerente administrativo. E um operário disse que se aprende mais quando se erra. De um modo geral os funcionários e operários declararam que lidar com o erro não é algo traumático, agressivo por parte das gerências, mas algo sobre o que sempre se conversa. No estudo de Leitão e Kurtz (2005), os operários, de forma unânime, diziam que na Femaq não havia "bronca", só conversa. E neste estudo, um auxiliar administrativo, em outra empresa, afirmou que quando ocorriam erros se procurava saber o motivo, mas de forma não-agressiva.

Nos depoimentos as relações entre as famílias formadas na análise surgem com freqüência e as implicações para a aprendizagem estão freqüentemente presentes. Como nesse depoimento sobre práticas não-formais no que se refere ao domínio pessoal: 
É interessante (a questão do treinamento) porque uma das meninas que está fazendo especialização em marketing conta na hora do café o que o professor disse (...) quem pega essa conversa está aprendendo também. Às vezes o investimento (em treinamento) é maior em um funcionário, mas é que nem aquela história de jogar uma pedra na água, que vai criando uma onda e depois outra e assim vai.

(Secretária)

Pensamento sistêmico: essa família, formada pela categoria única da "coletividade", aparece principalmente em depoimentos onde se demonstra compreensão da existência de dependência entre as partes.

Todo mundo sabia que se melhorasse um pouco, o serviço como um todo ia melhorar. Se a (qualidade do serviço) recepção melhora, a minha área (convênios) acaba melhorando também porque as fichas já vêm preenchidas de uma forma que facilita para a gente. E se o nosso serviço melhora, as funcionárias do outro setor (pagamentos) também. É por isso que todo mundo ganha.

(Auxiliar administrativo)

A gente trabalha em conjunto. Por exemplo, se falta uma peça, a produção não vai para a frente. A empresa depende de cada um de nós.

(Operário)

As entrevistas indicam uma mentalidade dominante de ajuda ao outro, visão do todo e objetivos coletivos, independentemente do setor examinado e da empresa representada. O sentimento coletivo é preponderante nas quatro empresas.

Referindo-se à tomada de decisão em sua empresa, diz uma gerente administrativa: "eu ocupo um cargo na empresa em que, em outros lugares, eu talvez me sentisse sozinha. Mas (aqui) são raros os momentos em que eu tenho de tomar uma decisão sozinha. As decisões são calcadas na comunhão com o outro". Este é um dos exemplos onde o sentido de coletividade se associa a uma visão compartilhada da gestão, com implicações na aprendizagem em equipe, ante a presença do diálogo antes do fazer e do decidir.

Ao longo da análise de conteúdo, em diversos momentos, pode-se registrar a presença de categorias distintas, de diferentes famílias em um mesmo trecho de um depoimento, demonstrando as inter-relações existentes entre essas categorias e famílias. Elas podem ser visualizadas como uma rede de relações onde os valores (modelos mentais) surgem com um elemento central nessa rede, os valores de EdC, absorvidos nas leituras e nas palestras de Chiara Lubich, líder do movimento focolarino. 


\section{Conclusão}

As duas etapas da pesquisa, a análise estatística e a análise de conteúdo, não mostraram incongruências ou discrepâncias sensíveis entre si. O nível de aceitação das 14 características testadas na primeira etapa, que penetram as famílias da análise de conteúdo, foi considerável.

Houve suficiente evidência da presença das 14 características testadas nas quatro empresas de EdC. E a análise de conteúdo das entrevistas em profundidade possibilitou a emergência de categorias compatíveis com as cinco disciplinas de Peter Senge. Então, quando se coloca a pergunta de se as empresas de economia de comunhão são organizações de aprendizagem, pode-se concluir pela existência de considerável similaridade entre as duas concepções de organização, em que pese algumas especificidades existentes entre elas. Elas seriam "organizações que aprendem" por facilitarem o aprendizado de seus membros de forma a possibilitar contínua transformação (Hawkins, 1991), principalmente para a forma EdC de gerir pessoas, pela qual todas essas empresas têm de passar, mesmo as que começaram a existir no projeto.

A diferença está, particularmente, no peso da espiritualidade da unidade que influencia os modelos mentais (valores) de seus dirigentes e na presença do amor-comportamento nas empresas de EdC. Esses dois elementos são o coração do ideário que orienta esse projeto e que têm forte influência sobre suas lideranças. A importância das lideranças, nesse projeto, é marcante, sobretudo porque elas não vêem de forma puramente instrumental o ser humano, ou seja, como mão-de-obra ou como consumidor. Partem de uma visão substantiva para chegar a suas funções instrumentais na vida (Almeida, 2002).

Este esforço de aproximação da realidade de EdC levou estes pesquisadores à perspectiva de Hawkins (1991), inspirada em Gregory Bateson, pela qual essas empresas estariam pondo em prática um aprendizado de nível III. Um nível que introduz a dimensão espiritual para dar sentido aos outros níveis de aprendizado: o prático e o estratégico. Para Bateson, o nível III é um estado de esclarecimento onde se atinge um alto nível de consciência, que permite a libertação das perspectivas e barreiras dos paradigmas dominantes. Nele, se é capaz de ver por meio desses paradigmas (em vez de ver com eles) e também de mudá-los (Hawkins, 1991).

No projeto de EdC, todavia, o termo "espiritual" pode ser entendido em seu sentido místico-religioso e não como uma capacidade superior do cérebro humano, como o biólogo e antropólogo inglês Gregory Bateson o utiliza. O caso EdC parece mostrar aqui uma ponte entre a concepção teórica de Bateson, usada por Hawkins, e a prática das lideranças daquele projeto, conforme seus relatos e o testemunho de seus funcionários, captados pelos pesquisadores. E é 
a partir dessa visão substantiva do ser humano que essas empresas parecem estar possibilitando a aprendizagem dos meios capazes de facilitar múltiplos tipos de microssistemas sociais, no contexto da organização, deixando margem para relacionamentos interpessoais menos dependentes das pressões da sociedade capitalista, como observava Guerreiro Ramos (1981:115) em sua crítica ao poder inerente a uma política cognitiva centrada no mercado.

Tal particularidade da economia de comunhão está fundada na forte presença do movimento dos focolares. Movimento e projeto parecem indissociáveis e a presença do movimento pode ser um fator explicativo para a existência de indutores à aprendizagem naquelas empresas. Pode-se perguntar se empresas eticamente orientadas, mas onde esteja ausente essa motivação transcendente, apresentariam o mesmo resultado. Alguns empresários de EdC acreditam que não. O modo EdC de administrar não poderia ser implantado por algum consultor desavisado, pois provém da interioridade daquele que administra.

Essa questão pode ser associada a outra, referente a um provável relacionamento entre a expansão do movimento e a expansão do projeto de EdC, inclusive no que tange à continuidade dos resultados econômico-financeiros satisfatórios que essas empresas vêm apresentando (Brandalise, 2003), uma vez que o bom relacionamento com seus stakeholders é um dos indutores desses resultados. A fonte do diferencial competitivo, a qualidade dos relacionamentos que elas apresentam (Pinto e Leitão, 2006), pode estar na forte presença do movimento, embora não se fale dele no interior das empresas, nem se vejam cartazes ou dizeres que o lembrem. Muitos funcionários desconhecem o movimento e o projeto, pois a idéia de sua idealizadora é que ele se manifeste pelas ações das lideranças e não por puro discurso. E é isso que parece estar ocorrendo, em um processo gradativo de formação de cultura nessas empresas, que favorece significativamente o aprender. Tanto o aprender dos processos como os comportamentos para ser EdC, com sua forma substantiva de ver as empresas e o mundo dos negócios.

\section{Referências bibliográficas}

ALMEIDA, M. A empresa de economia de comunhão: possibilidade de valorização da racionalidade substantiva na organização econômica? 2002. Dissertação (Mestrado em Administração) - Departamento de Administração, Pontifícia Universidade Católica do Rio de Janeiro, Rio de Janeiro.

ARGYRIS, C.; SCHON, D. Organizational learning. New York: Addisson-Wesley, 1978. 
BARDIN, L. Análise de conteúdo. Lisboa: Edições 70, 1977.

BRANDALISE, L. A. A finalidade do lucro para as empresas de economia de comunhão. 2003. Tese (Doutorado) - Faculdade de Economia, Administração e Contabilidade, Universidade de São Paulo, São Paulo.

BRUNI, L. Comunhão e as novas palavras em economia. São Paulo: Cidade Nova, 2005.

CALLAHAN, J. J.; SCHWANDT, D. R. The academy as social system: a meta-framework for organizational learning. In: ORGANIZATIONAL LEARNING 3D CONFERENCE. Proceedings... Lancaster University, UK, p. 1-33, June 6-8, 1999. Disponível em: < http://notes, lancs.ac.uk/pub/o13.nsf/All?Open View $>$.

CAPRA, F. A teia da vida. São Paulo: Cultrix, 1997.

COHEN, M. D.; SPROUL, L. S. Introduction. Organization Sciences (Special issue on organizational learning), v. 2, n. 1, 1991.

GIOIA, D. A.; PITRE, E. Multiparadigm perspectives on theory building. Academy of Management Review, v. 15, n. 4, p. 584-602, 1990.

GONÇALVES, H. H. A. B. Q. A experiência dos pioneiros da economia de comunhão na liberdade no primeiro decênio (1991-2001) no Brasil: absurdo e graça da mudança de mentalidade do empresário. 2005. Tese (Doutorado) - Coppe, Universidade Federal do Rio de Janeiro, Rio de Janeiro.

; LEITÃO, S. P. Empresas de economia de comunhão: o caso Femaq. Revista de Administração Pública, v. 35, n. 6, p. 1145-1170, nov./dez. 2001.

GUSTAVSSON, B. Toward a transcendent epistemology of organizations: new foundations for organizational change. Journal of Organizational Change Management, v. 14, n. 4, 2002.

HARDY, C.; CLEGG, S. R. Representações. In: CLEGG, S. R.; HARDY, C.; NORD, W. R. Handbook de estudos organizacionais. São Paulo: Atlas, 2001. v. 2.

HAWKINS, P. The spiritual dimension of the learning organization. Management Education and Development, v. 22, n. 2, p. 172-187, 1991.

KOFMAN, F; SENGE, P. Communities of commitment: the heart of learning organizations. Organizational Dynamics, v. 22, n. 2, p. 5-23, Autumn 1993.

LAND, G.; JARMAN, B. Para além do ponto de ruptura. In: RAY, M.; RINZLER, A. (Orgs.). O novo paradigma dos negócios. São Paulo: Cultrix, 1997.

LAPIERRE, L. Interioridade, gestão e organização da realidade psíquica como fundamento da gestão. In: CHANLAT, J.-F. (Coord.). O indivíduo na organização: dimensões esquecidas. São Paulo: Atlas, 1994. v. 2. 
LEITÃO, S. P.; CARVALHO, P. R. P. Organizações de aprendizagem: resistências culturais. Revista de Administração Pública, v. 33, n. 4, p. 25-46, jul./ago. 1999.

; KURTZ, R. M. Relacionamentos interpessoais e aprendizagem na economia de comunhão: o caso Femaq. Revista de Administração Pública, v. 39, n. 4, p. 913-937, jul./ago. 2005.

LUBICH, C. A experiência economia de comunhão: da espiritualidade da unidade. In: BRUNI, L. (Org.). Economia de comunhão, uma cultura econômica em várias dimensões. São Paulo: Cidade Nova, 2002.

. Economia de comunhão, história e profecia. São Paulo: Cidade Nova, 2004.

MACHADO, A. C. M. Economia de comunhão: elementos para uma teoria organizacional. 2006. Tese (Doutorado) - Departamento de Engenharia Industrial, Pontifícia Universidade Católica do Rio de Janeiro, Rio de Janeiro.

MATURANA, H. Emoções e linguagem na educação e na política. Belo Horizonte: UFMG, 2001.

; BUNNELL, P. Biosphere, homosphere and robosphere: what has to do with business? In: SOCIETY FOR ORGANIZATIONAL LEARNING MEMBER'S MEETING. Proceedings... Mherst, 1998.

; VARELA, F. A árvore do conhecimento. Porto Alegre: Editorial Psy, 1995.

MENDES, N. M. D. Relações interpessoais: um caso de estudo das empresas EdC, 2003. Dissertação (Mestrado em Recursos Humanos e Administração) — Universidade Federal da Paraíba, João Pessoa.

PINTO, M. C. S. A economia de comunhão sob o olhar da teoria dos stakeholders. 2004. Tese (Doutorado em Administração) — Departamento de Administração, Pontifícia Universidade Católica do Rio de Janeiro, Rio de Janeiro.

; LEITÃO, S. P. Economia de comunhão: empresas para um capitalismo transformado. Rio de Janeiro: FGV, 2006.

RAMOS, A. G. A nova ciência das organizações. Rio de Janeiro: FGV, 1981.

SENGE, P. A quinta disciplina. São Paulo: Best Seller, 1990.

et al. A quinta disciplina: cadernos de campo. Rio de Janeiro: Qualitymark, 1999.

VILLARDI, B. Q.; LEITÃO, S. P. Organizações de aprendizagem e mudança organizacional. Revista de Administração Pública, v. 34, n. 3, p. 53-70, maio/jun. 2000. 